\title{
The Factors Affecting the Length of Stay in the Intensive Care Units of Pertamina Central Hospital in Indonesia Related to Healthcare Associated Infections
}

\author{
Nanang Sugiarto ${ }^{1}$ and Ede Surya Darmawan ${ }^{2}$ \\ 1. Pertamina Center Hospital, Pertamina Center Hospital, Jakarta 12120, Indonesia
}

2. Department of Health Policy and Administratioin, Faculty of Public Health, University of Indonesia, West Java 16424, Indonesia

\begin{abstract}
HAIs (healthcare associated infections) are important issues and can cause increased morbidity, mortality, and extension of hospital care time. In Indonesia, HAIs in hospitals are most prevalent in the intensive care unit. Within the last three years, BOR (bed occupancy ratio) of Pertamina Hospital has reached 61.77\% in 2011 and reached $66.78 \%$ in 2013. The hospital has been faced with increased number of inpatients and longer length of stay leading to greater likelihood of the risk of HAIs. The purpose of this study is to identify the factors associated with length of stay (more than $3 \times 24 \mathrm{~h}$ ) in the intensive care unit, and the prevalence rates of HAIs from January 2011 to December 2012. The study uses quantitative cross-sectional survey design with secondary data from the medical record samples of 897 patients and primary data from questionnaires medical personnel of 90 people. Data collection was done through document review of medical records and the data from the Hospital Infection Control Team. The results of the study have shown that there are four factors from medical records related to length of stay, namely, age, the use of invasive medical devices, nutritional status and comorbidities. The results of the questionnaire have shown that majority of the hospital staffs have already had knowledge and attitudes as well as behaviors that adhere to universal precautions. HAIs prevalence in Pertamina Central Hospital in 2011 was $1.15 \%$, and decreased to $0.27 \%$ in 2012; yet, it was still below $1.5 \%$ in accordance with the national standards from Ministry of Health of Indonesia. Finally, there was a relationship between the occurrence of HAIs and length of stay. It was then recommended to adapt Five Moments for Hand Hygiene Guideline from the WHO (World Health Organization) to reduce HAIs in the Hospital.
\end{abstract}

Key words: Hospital administration, infection control, HAIs, LOS (length of stay), intensive care unit.

\section{Introduction}

Nosocomial infections have been known since ancient times. First recorded in 1847, these types of infections are still popular among medics and hospitals up to the present time and are considered as a serious problem that causes direct or indirect death of patients. Currently, the term has begun to be replaced by a new term called HAIs (healthcare associated infections), in which it covers broader understanding to refer to infections happen not only in hospitals but also in other health care facilities [1].

Corresponding author: Ede Surya Darmawan, Ph.D., senior lecturer, research field: health services policy and administration. $\quad$ E-mail: $\quad$ edesurya@ui.ac.id; edesurya@gmail.com.
The occurrence of nosocomial infections will cause a lot of losses; among others are longer LOS (length of stay) as well as increased pain and costs for patients [1-4].

According to the Ministry of Health of Indonesia (2003), around $20 \%-45 \%$ of the nosocomial infections in hospitals occur in the ICU (intensive care unit) - since it is related to the severity of patients' diseases and the use of invasive medical devices making it more likely to affect LOS.

Longer LOS for inpatients increases the risk of getting nosocomial infections compared to shorter LOS. Longer LOS is the dominant factor affecting nosocomial infections in hospitals $[2,3]$.

Currently, RSSP (Pertamina Central Hospital) has a 

Indonesia Related to Healthcare Associated Infections

total capacity of 366 beds with increasing average of BOR (bed occupation rate) in the last 3 years $-61.77 \%$ in 2011 and reached $66.78 \%$ in 2013. Similarly, LOS has also increased in the last 3 years, so vigilance needs to be improved due to the greater likelihood of the risk of infection. Thus, we need to find out the prevalence of nosocomial infections/HAIs in the intensive care unit of RSPP, and the factors are associated with LOS in the ICU and SU (stroke unit) which is linked to the occurrence of nosocomial infections/HAIs during January 2011 to December 2012.

\section{Methods}

This study used a cross-sectional quantitative method. Samples were taken from medical records of patients treated more than $3 \times 24 \mathrm{~h}$ in the intensive care unit from January 2011 to December 2012 and there were 897 patients in this research. Supporting data was gathered using questionnaires distributed to the intensive care unit personnel (doctors and nurses) in the form of primary data. The measurement scale used in the questionnaire was the Likert Scale.

In this study, validity and reliability tests were done with SPSS software version 21.00 on each questionnaire as many as two times. The first questionnaire was distributed to 30 respondents (doctors and nurses) after the 20 questions related to knowledge and 20 questions related to attitude were validated and revised into each 18 questions; no change was done to 20 questions related to actions/behaviors since they were all valid. Questionnaires were distributed to 90 respondents involved in the study (doctors and nurses in SU and ICU) and the results were considered valid and reliable. Before processing, the secondary data collected from survey respondents was checked in term of completeness of the data filled out. Selection was done, in which the data met the inclusion criteria would be included in the study. The selected data was then coded for each question or variable studied. Furthermore, the data was entered into the SPSS software for data processing.

\section{Results}

In the data processing on patients' medical records, four factors associated with long LOS were obtained, namely age, comorbidities, nutritional status and use of invasive medical devices.

\subsection{Patients' Length of Stay}

The shortest LOS for patients in the intensive care units was 4 days, while the longest LOS was 91 days as shown in Table 1.

Among 897 patients, the highest frequency of LOS was 8-14 days with as many as 327 patients (36.5\%), and the lowest frequency of LOS was 4-7 days with as many as $283(31.5 \%)$ patients. This means that the average LOS for the patients is $14 \times 24$ hours.

\subsection{The Characteristics Based on Patients'Age}

Distribution of age in this study follows the method developed by Hurlock [5] and combined with the guideline by Indonesian Pediatric Association, namely:

(1) early adulthood: starting at age of 18 until age of 40;

(2) middle adulthood: starting at age of 41 to 60 years;

(3) late adulthood: starting at the age of 60 years to death.

The age under 18 years is classified as children according to the guideline by Indonesian Pediatric Association (Table 2).

Table 1 Frequency distribution of patients based on length of stay.

\begin{tabular}{lll}
\hline Length of stay (days) & Number & Percentage \\
\hline 4-7 days & 283 & $31.5 \%$ \\
8 -14 days & 327 & $36.5 \%$ \\
$>$ 14 days & 287 & $32.0 \%$ \\
Total & 897 & $100 \%$ \\
\hline
\end{tabular}

Table 2 Frequency distribution of patients by age.

\begin{tabular}{lll}
\hline Age (year) & Number & Percentage \\
\hline $0-17$ & 48 & $5.4 \%$ \\
$18-40$ & 82 & $9.1 \%$ \\
$41-60$ & 329 & $36.7 \%$ \\
$>60$ & 438 & $48.8 \%$ \\
Total & 897 & $100 \%$ \\
\hline
\end{tabular}



Indonesia Related to Healthcare Associated Infections

Once the age variable was classified, the age range with the biggest percentage was the one over 60 , as much as $48.8 \%$. The percentage for the age range of 41-60 was $36.7 \%$, the percentage for the age range of $18-40$ was $9.1 \%$, and the percentage for age range of $0-17$ was $5.4 \%$.

\subsection{Comorbidity Diagnosis}

Patients treated in the intensive care unit can be diagnosed to have more than three types of comorbidities; yet, they may not have any comorbidity. Thus, the researchers divided the categories of comorbidity diagnosis into two categories, namely the presence and the absence of comorbidity. The most common/frequent comorbidities are diabetes mellitus, upper respiratory infection (Pneumonia), coronary disease, stroke, etc..

Once the variable of comorbidity diagnosis was classified, it was found out in Table 3 that among 897 patients treated in ICU and SU, as many as 835 patients (93.1\%) were found to develop comorbidities. This means that the majority of the patients in the intensive care units develop comorbidities in addition to their underlying diseases.

\subsection{The Use of Invasive Medical Devices}

Based on the statistics obtained, the average invasive medical devices used by the patients were 3.18 , with a mean of three and the highest number of invasive medical devices used by the patients was seven. The lowest number of invasive medical devices used by the patients was one. Further, the variable on the use of invasive medical devices is classified into two categories based on the median value.

In Table 4, the use of invasive medical devices $(\geq 3)$ was applied to 527 patients (58.8\%), which was higher

Table 3 Frequency distribution of patients based on comorbidity.

\begin{tabular}{lll}
\hline Comorbidity diagnosis & Number & Percentage \\
\hline Presence & 62 & $6.9 \%$ \\
Absence & 835 & $93.1 \%$ \\
Total & 897 & $100 \%$ \\
\hline
\end{tabular}

than the use of invasive medical devices $(<3)$ that was only applied to 370 patients $(41.2 \%)$. The most frequent devices are central/intravenous infusion, intubation with ventilator, etc..

\subsection{Nutritional Status}

Good and bad nutritional status can be determined based on the results of consultation to the Physician Nutrition Specialists at RSPP. Based on the status of albumin level, below-normal albumin level belongs to malnutrition status, while normal albumin level belongs to good nutrition status $(\mathrm{N}: 3.5-5.0 \mathrm{~g} / \mathrm{dL})$.

The results of the analysis show that the total patients were 897, among which the albumin level of 548 patients was below normal $(\mathrm{N}: 3.5-5.0 \mathrm{~g} / \mathrm{dL})$ (Table 5). It means that $61.1 \%$ of the patients in the intensive care units held the malnutrition status, while the rest of $38.9 \%$ held good nutritional status.

\subsection{The Results of Analyses on Factors Affecting Length of Stay in Intensive Care Units}

Table 6 shows that the average patients at the age of more than 60 years were dominating at all categories of

Table 4 Frequency distribution of patients based on the use of invasive medical devices.

\begin{tabular}{lll}
\hline The use of invasive medical devices & Number & Percentage \\
\hline The use of invasive medical devices $<3$ & 370 & $41.2 \%$ \\
The use of invasive medical devices $\geq 3$ & 527 & $58.8 \%$ \\
Total & 897 & $100 \%$ \\
\hline
\end{tabular}

Table 5 Frequency distribution of patients based on nutritional status.

\begin{tabular}{lll}
\hline Nutritional status & Number & Percentage \\
\hline Malnutrition & 548 & $61.1 \%$ \\
Good & 349 & $38.9 \%$ \\
Total & 897 & $100 \%$ \\
\hline
\end{tabular}

Table 6 The relationship between patients' age and length of stay.

\begin{tabular}{lllll}
\hline \multirow{2}{*}{ Age (year) } & \multicolumn{4}{c}{ LOS } \\
\cline { 2 - 4 } & $4-7$ & $8-14$ & $\geq 14$ & Total \\
\hline Age $>60$ & 137 & 159 & 142 & 438 \\
Age 41-60 & 98 & 114 & 117 & 329 \\
Age 18-40 & 26 & 33 & 23 & 82 \\
Age 0-17 & 22 & 21 & 5 & 48 \\
Total & 283 & 327 & 287 & 897 \\
\hline
\end{tabular}



Indonesia Related to Healthcare Associated Infections

Table 7 The relationship between comorbidities and length of stay.

\begin{tabular}{lllll}
\hline \multirow{2}{*}{ Comorbidity } & \multicolumn{4}{c}{ LOS } \\
\cline { 2 - 4 } & $4-7$ & $8-14$ & $\geq 14$ & Total \\
\hline Absence & 258 & 298 & 279 & 835 \\
Presence & 25 & 29 & 8 & 62 \\
Total & 283 & 327 & 287 & 897 \\
\hline
\end{tabular}

Table 8 The relationship between nutritional status and length of stay.

\begin{tabular}{lllll}
\hline \multirow{2}{*}{ Nutritional status } & \multicolumn{4}{c}{ LOS } \\
\cline { 2 - 4 } & $4-7$ & $8-14$ & $\geq 14$ & Total \\
\hline Malnutrition & 186 & 185 & 177 & 548 \\
Good & 97 & 142 & 110 & 349 \\
Total & 283 & 327 & 287 & 897 \\
\hline
\end{tabular}

Table 9 The relationship between the use of invasive medical device and length of stay.

\begin{tabular}{lllll}
\hline Invasive medical & \multicolumn{4}{c}{ LOS } \\
\cline { 2 - 4 } devices & $4-7$ & $8-14$ & 14 & Total \\
\hline $\begin{array}{l}\text { The use of invasive } \\
\text { medical devices } \geq 3\end{array}$ & 205 & 217 & 105 & 527 \\
$\begin{array}{l}\text { The use of invasive } \\
\text { medical devices }<3\end{array}$ & 78 & 110 & 182 & 370 \\
Total & 283 & 327 & 287 & 897 \\
\hline
\end{tabular}

LOS, ranging from 4-7 days, 8-14 days, and more than 14 days. In all LOS categories, this age group had a high percentage compared to the other age groups. Thus, it means that the age of patients has positive relationship with LOS.

Based on the analysis of relationship between the diagnosis of comorbidities and LOS (Table 7), patients who had a diagnosis of comorbidities were the ones treated between 8-14 days, more than 14 days or longer LOS; thus, it can be concluded that there are positive relationship between comorbidity diagnosis and LOS of patients.

For LOS greater than or equal to 14 days, the percentage of respondents with malnutrition status was $32.30 \%$ (Table 8 ). Most of the patients of each category in LOS have malnutrition status. Thus, it can be concluded that there are a relationship between nutritional status and the length of stay in intensive care units.

Patients using invasive medical devices $(\geq 3)$ were those staying in the intensive care units around 8-14 days (Table 9), and it means that there is a relationship between the use of invasive medical device and the length of stay.

\subsection{The Results of Multivariate Analysis}

Table 10 shows the summary of factors related to the length of stay of patient in the intensive cafe unit as part of multivariat analysis. From the multivariate analysis, it shows that all of the variables like age, nutritional status, comorbidity diagnosis, and the use of invasive medical devices had a significant relationship with length of stay. After being merged with the other variables, the nutritional status, which was not significant in the bivariate analysis, became a significant relationship because the significance level was visible for LOS of 8-14 days, which was 0.022 and $P<0.05$, so it can be concluded that there was a relationship between nutritional status and length of stay.

3.8 The Results of Analysis of Questionnaire for the Medical Officers (Doctors and Nurses)

The questionnaire was used to measure the knowledge, attitudes, behaviors/actions, environment, and management policy. We surveyed 90 staffs consisting of 65 nurses and 25 medical doctors.

\subsubsection{The Knowledge of the Medical Officers}

According to stardard from Hospital Infection Control Team, a respondent will be categorized in a good knowledge if the respondents answered 16 questions (or around 80-90\%) of the 18 questions correctly. Table 11 shows that majority of the respondents have a good knowledge about patient safety and universal precautions.

\subsubsection{The Attitude of the Medical Officers}

Table 12 shows that most of respondents $(82.22 \%)$ have a good attitudes to patient safety and universal precaution. This condition is inline with the expecation of Pertamina Hospital that just conducted on patient safety and universal precautions as part of preparation to apply JCI (Joint Commission International) Accreditation. 

Indonesia Related to Healthcare Associated Infections

Table 10 Summary of the four factors.

\begin{tabular}{|c|c|c|c|}
\hline Factor & Measurement results & Number & Percentage \\
\hline \multirow{3}{*}{ Length of Stay } & $\geq 14$ days & 287 & $32.0 \%$ \\
\hline & 8-14 days & 327 & $36.5 \%$ \\
\hline & 4-7 days & 283 & $31.5 \%$ \\
\hline \multirow{4}{*}{ Age } & Age $>60$ & 438 & $48.8 \%$ \\
\hline & Age $41-60$ & 329 & $36.7 \%$ \\
\hline & Age $18-40$ & 82 & $9.1 \%$ \\
\hline & Age 0-17 & 48 & $5.4 \%$ \\
\hline \multirow{2}{*}{ Comorbidity } & With & 835 & $93.1 \%$ \\
\hline & Without & 62 & $6.9 \%$ \\
\hline \multirow{2}{*}{$\begin{array}{l}\text { The use of } \\
\text { invasive medical } \\
\text { devices }\end{array}$} & $\begin{array}{l}\text { The use of invasive } \\
\text { medical devices } \geq 3\end{array}$ & 527 & $58.8 \%$ \\
\hline & $\begin{array}{l}\text { The use of invasive } \\
\text { medical devices }<3\end{array}$ & 370 & $41.2 \%$ \\
\hline \multirow{2}{*}{ Nutritional status } & Malnutrition & 548 & $61.1 \%$ \\
\hline & Good & 349 & $38.9 \%$ \\
\hline Total & & 897 & $100.0 \%$ \\
\hline
\end{tabular}

Table 11 Frequency distribution of medical officers based on knowledge.

\begin{tabular}{lll}
\hline Knowledge & Number & Percentage \\
\hline Good & 69 & $76.67 \%$ \\
Lack & 21 & $23.33 \%$ \\
Total & 90 & $100 \%$ \\
\hline
\end{tabular}

Table 12 Frequency distribution of medical officers based on attitudes.

\begin{tabular}{lll}
\hline Attitude & Number & Percentage \\
\hline Good & 74 & $82.22 \%$ \\
Lack & 16 & $17.78 \%$ \\
Total & 90 & $100 \%$ \\
\hline
\end{tabular}

3.8.3 The Behaviors and Actions of the Medical Officers

The adherent behavior to patient safety and universal precaution adopted the WHO's (World Health Organization's) Five Moments and Six Steps for Hand Hygiene Guideline (WHO, 2009) [6]. Therefore, Table 13 shows that most of medical staffs $(73.3 \%)$ were categorized as adhere behavior.

In addition to using the questionnaire, the researchers also conducted direct observation of both nurses and doctors on hand hygiene.
The medical officers perfomed only four of the five Moments of Hand Hygiene Guideline, which is the moment after contact with blood or body fluids. The average of adherence level for doctors were $62 \%$ and $66 \%$ for nurses (Table 14).

\subsubsection{Hospital Management Policy}

The management policy at RSPP on the general service of hospital includes the criteria for patients to be taken in and out of intensive care units as well as the policy on the prevention of HAIs.

In Table 15, 68.89\% of the respondents can be categorized as adherent, while the rest of $31.11 \%$ belong to the category of non-adherent.

3.8.5 The Condition of the Intensive Care Units

In Table 16, most of respondents (65.56\%) perceived that the environmental condition of intensive care units was met with the standard or in a good condition. This condition is related to facts that all intensive care units in the hospital have already equiped with proper lighting, interval bed, hand washer, walls, and temperature control as regulated by Ministry of Health Indonesia 2011 [1, 2].

\subsubsection{Prevalence of Nosocomial Infections}

There were four types of nosocomial infections in the intensive care unit based on PPIRS data: UTI: urinary tract infection (the infection of urinary tract); SSI: surgical site infection; VAP: ventilator acquired pneumonia; BSI: primary bloodstream infection.

Ninety nine out of 897 patients got HAIs and the highest percentage was $42.43 \%$ due to VAP infections (Table 17).

Table 13 Distribution of medical officers based on behaviors.

\begin{tabular}{lll}
\hline Behaviors & Number & Percentage \\
\hline Adherent & 66 & $73.30 \%$ \\
Non-adherent & 24 & $26.70 \%$ \\
Total & 90 & $100 \%$ \\
\hline
\end{tabular}

Table 14 The results of direct observations on hand hygiene moments.

\begin{tabular}{llllll}
\hline Type of staff & Before contact & After contact & Before performing aseptic actions & After contact with the environment & Average \\
\hline Doctors & $50 \%$ & $65 \%$ & $60 \%$ & $73 \%$ & $62 \%$ \\
Nurses & $56 \%$ & $66 \%$ & $70 \%$ & $75 \%$ & $66 \%$ \\
\hline
\end{tabular}



Indonesia Related to Healthcare Associated Infections

Table 15 Questionnaire data on management policy.

\begin{tabular}{lll}
\hline Policy & Number & Percentage \\
\hline Adherent & 62 & $68.89 \%$ \\
Non-adherent & 28 & $31.11 \%$ \\
Total & 90 & $100 \%$ \\
\hline
\end{tabular}

Table 16 Questionnaire data on the condition of the intensive care units.

\begin{tabular}{lll}
\hline Condition & Number & Percentage \\
\hline Following the guideline & 59 & $65.56 \%$ \\
Not following the guideline & 31 & $34.44 \%$ \\
Total & 90 & 100 \\
\hline
\end{tabular}

Table 17 Descriptive variables for nosocomial infections.

\begin{tabular}{lll}
\hline Types of infections & Number & Percentage \\
\hline UTI & 21 & $21.21 \%$ \\
SSI & 3 & $3.03 \%$ \\
VAP & 42 & $42.43 \%$ \\
BSI & 33 & $33.33 \%$ \\
Total & 99 & $100 \%$ \\
\hline
\end{tabular}

Source: PPIRS data 2011 and 2012 (re-processed).

Table 18 The relationship of length of stay and nosocomial infections (HAIs).

\begin{tabular}{|c|c|c|c|}
\hline \multirow{2}{*}{ LOS } & \multicolumn{2}{|c|}{ Infections } & \multirow{2}{*}{-Total } \\
\hline & Presence & Absence & \\
\hline$>14$ days & 83 & 187 & 270 \\
\hline 8-14 days & 12 & 332 & 344 \\
\hline 4-7 days & 4 & 279 & 283 \\
\hline Total & 99 & 798 & 897 \\
\hline
\end{tabular}

3.8.7 The Relationship of Length of Stay and Nosocomial Infections

The results of analysis between the length of stay and nosocomial infections can be seen in Table 18 .

In Table 18, it can be seen that patients with LOS more than 14 days, have the highest level of HAIs (30.74\%). It can be concluded that there is a relationship between LOS and nosocomial infections (HAIs).

\section{Discussion}

\subsection{Limitation of the Study}

The researchers realized that the used of secondary data has an advantages of cost and time efficiency, but it has some limitations. The data cannot be obtained from the medical records, so a survey to the staff (both doctors and nurses) of the intensive care units should be done.

Literatures related to HAIs so far are still limited in Indonesia and not easy to access. To overcome this situation, we have tried downloading articles/journals/e-book related to the topic of the study.

\subsection{Factors Affecting the Length of Stay Obtained from the Medical Records of Patients}

\subsubsection{Age of Patients}

The patients at intensive care units usualy come from different ages group from children up to the elderly. However, in our study most of the patients were the elderly with more 60 years old (48.8\%). According to Czeresna [7], elderly patients have several characteristics such as multiple pathology or suffer from more than one disease (co-morbidity) and mostly chronic degenerative; decline of physiologic reserve power or immuno deficience, changes in the classic signs and symptoms of the diseases, and disruption of the functional status of the geriatric patients. The functional status is a person's ability to do activities of daily life. Therefore, it is reasonable that most of the elderly patients who are hospitalized are easy to fall into a state of critical illness. Elderly patients are usually transferred to the critical intensive care units. To reduce these impacts on the elderly people, precautions before elderly patients entering the ICU/SU must be taken (especially when patients are previously treated in non-intensive care units), when the patients are taken care by relevant specialists in the multidisciplinary team work, and are routinely conducted with medical and clinical audit.

\subsubsection{Comorbidity}

In term of co-morbidity the patients are grouped into two categories, based on the presence or absence of co-morbidity. In this research, most of patients treated at intensive care unit with comorbidity were about 838 people $(93.11 \%)$ and the rest were without co-morbidity. Therefore it can be concluded that most 

Indonesia Related to Healthcare Associated Infections

of the patients treated in intensice care unit were patients with multi-pathology. If we relate to the fact from previous section that about $48.8 \%$ of patient at ICU was elderly, then it is understood that it is because of the presence of multi-pathology and elderly that they need ICU, as mentioned by Czeresna [7].

\subsubsection{The Use of Invasive Medical Device}

During our research, we found some patients treated in the intensive care unit were using seven invasive medical devices such as intravenous infusion, NGT (nasogastric tube), installation of CVP/CVC (central venous pressure/central venous catheter), urinary catheters, ETT (endotracheal tube), ventilators and surgical wound. For the purpose of this study, we divided the uses of invasive medical devices into two category such as $\geq 3$ devices and $<3$. The use of invasive medical devices $\geq 3$ was applied to 528 patients $(58.67 \%)$, which was higher than the use of invasive medical devices $<3$ that was only applied to 372 patients (41.33\%). Therefore it can be conclude that mostly the patients who are treated in the intensive care units were using invasive medical devices. According to Richard et al. [8], the use of invasive medical devices is contributing to the factor of nosocomial infections. The longer use of mechanical ventilators, urinary catheters, intravenous therapy and infusion will increase the risk of nosocomial infections in the intensive care units [12].

\subsubsection{Nutritional Status}

To determine the nutritional status of inpatients, the hospitals ideally refers to the classification of BMI (body mass index) by WHO for Asian populations, which are divided into six categories namely underweight, normal weight, overweight, pre-obese, obesity 1 , and obesity 2 . However, due to limited data of the height and weight of patients, then we consulted physician nutrition specialists at the hospital, and concluded that the nutritional status was determined by using parameter of albumin. When the albumin was low, it shows malnutrition. But if the albumin was normal, it can be concluded that a good nutrition $(\mathrm{N}$ :
3.5-5.0 g/dL). From the results above, 548 people have malnutrition $(61.1 \%)$ from 897 patients treated during 2011 to 2012. This is consistent with the theory of Escallon et al. [9], stating that injuries or serious illnesses will affect the need and metabolism of energy, proteins, carbohydrates and fat on critical conditions. Nevertheless, bivariate statistical test results showed that there was no significant corelation between nutritional status and the length of stay.

\subsubsection{Length of Stay}

The average of LOS for patients in the intensive care units was 14.36 days or more than 14 days or 2 weeks. This situation was one of the reasons why most of patients having more co-morbidity are probably infected by HAIs. This finding was inline with research of Cruse in Malangoni [10] that had mentioned infection risk will increase along with the increase of leng of stay of patients in the hospital. To reduce LOS in the intensive care unit, strengthening collaboration between doctors, nurses, and other hospital staffs is required. Moving the patients of operation/surgery post who needed monitoring or observation from ICU to a regular ward will reduce LOS and cost as well as risk of infections.

\subsection{Exogenous Factors and the Results of Questionnaire of the Medical Officers}

4.3.1 The Knowledge, Attitudes, and Behaviors of the Medical Officers (Doctors and Nurses)

To measure knowledge, attitude and behavior of medical staffs, we developed a questionarre consisting of 18 questions related to knowledge, 18 questions on attitudes, and 20 questions on behaviors. The number of respondents join in this survey was 90 . The results show that most of respondents $(76.67 \%)$ have good knowledge, good attitude $(82.22 \%)$, and good behavior or adhere to patient safety (73.3\%). This situation might be related to the facts that currently the hospital have been applying to get JCI accreditation since 2013 and all had already been given training on patient safety (including hand hygiene) and BLS (basic life 

Indonesia Related to Healthcare Associated Infections

support).

\subsubsection{Adhrence to Policy Hospital for Patient Safety}

Most of the respondent were adhere to the policy of hospital in term of patient safety. As mentioned above, one of the reasons was related to fact that currently the hospital is in the process of applying to get JCI accreditation whereas the hospital has already conducted series of dissemination to all criteria of JCI and quality of services of the hospital.

\subsubsection{Condition of the Intensive Care Units}

The majority of respondents stated that the condition of ICU and SU was good (65.56\%). As required by the Ministy of Health Indonesia 2011, the handbook of service provision for $\mathrm{HCU}$ (high care unit) and ICU at hospitals includes the intensive care units design, the lighting, the space of the beds (the minimum should be $2 \mathrm{~m}$ ), the liquid of disinfectant for hand hygiene, the disposal wash liquid and solid waste, kitchen sanitation, cleaning and laundry services, control of insects rat and nuisance animals, and traffic flow of people. Based on interviews with nurses in ICU and SU, there are some defects, such as walls made of porcelein but having partitions, the junctions between wall and floor making it difficult to clean and being a place for germs or pathogenic bacteria to grow up. The solution is renovations for each junction to make curving angles to make it easier to clean.

\subsection{Age of Patients and Length of Stay (LOS)}

Correlation test between age of patients and length of stay had shown postive relationship $(P<0.05)$. One of the reasons was due to the fact that the elderly have poor organs function and immune system deficiencies $[3,7]$. Therefore, it was recommended that hospital needs to provide special treatment for geriatric patients.

\subsection{Comorbidities and Length of Stay}

Correlation test between the presence of co-morbidity and length of stay had shown postive relationship $(P<0.05)$. Patients having more diseases or co-morbidiy treated in ICU will need more treatment, more medicines and more invasice devices, therefore there will be longer LOS in the ICU room. This finding was in line with the research of Santoso [11]. WHO mentioned that the presence of other diseases such as TB (tuberculosis), diabetes and malnutrition will led to longer LOS. The recommendation is that the patients should be treated by a multidisciplinary team with a single management (captain) as a team leader and to apply semi-closed system in the ICU.

\subsection{The Nutritional Status and Length of Stay}

Correlation test between nutritional status of patients and length of stay had shown no significance $(P>0.05)$. This finding was in contrary with general theory that malnutrition can make the patients complicated such as post-surgery infections, dehydration, deficiency, fever and long healing resulting in longer LOS. However, it is recommended that the hospital needs to create policy that ICU patients should also be taken care by nutrition specialists.

\subsection{The Use of Invasive Medical Devices and Length of} Stay

The biggest percentage of LOS for patients using invasive medical devices < 3 was $49.46 \%$ for those staying in the ICU for more than 14 days. The biggest percentage of LOS for patients using invasive medical devices $\geq 3$ was $41.17 \%$ for those staying in the ICU around 8-14 days. The results of the analysis show the correlation between the use of invasive medical devices and LOS. The more number of invasive medical devices use, the longer the LOS will be. This is in line with the results of the study by Yelda [12], stating that the longer of use mechanical ventilators, urinary catheters, intravenous therapy and infusion will increase the risk for nosocomial infections in the ICU. The recommendation is to limit the use of invasive medical devices and to remove the devices as soon as possible after consulting with the team, anesthetists, and consultant of intensive care in charge. 

Indonesia Related to Healthcare Associated Infections

\subsection{Multivariate Analysis}

Based on the combined analysis (multivariate) with multinomial logistic, it is found that all variables, i.e., age, comorbidities, nutritional status, and the use of invasive medical devices, correlated with length of stay. Nutritional status did not show significant difference in the bivariate analysis and multivariate analysis, but after being combined with other variables, it turned to have a relationship with LOS.

\section{Conclusions}

Based on the findings, there are several factors affecting LOS in ICU as follows:

The prevalence of the nosocomial infections in the ICU and SU at Pertamina Central Hospital was less than $1.5 \%$, which still met with standard of Ministry of Health Indonesia (2011) [1, 4].

Most of patients treated in ICU were the elderly (> 60 years old), with average LOS of 8-14 days. Nutritional status of patients based on albumin level testing was mostly in malnutrition (61.1\%), and mostly having co-morbidities, and mostly using multi invasive medical devices (more than three types of invasive medical devices).

The knowledge, attitudes and behavior of medical officers (doctors and nurses) in general was in good level and adhered to the existing policy of patient safety. Besides that, the preparation applying JCI accreditation has become co-factor of improvement knowledge, attitudes and behavior of medical officers to patient safety.

This research had found that LOS in ICU have positive relationship $(P<0.05)$ with age of patients, presence of co-morbidity, and multipple use of invasive medical devices. However, we also found that there was no relationship between LOS and nutritional status of patients $(P>0.05)$.

The multivariate analysis showed that there was a relationship between age, comorbidties, the use of invasive medical devices, and nutritional status (which was not significant through the bivariate analysis) and
LOS.

Pertamina Central Hospital was trying to improve patient safety conditions in line with the appliation process to JCI Acreditation.

\section{Recommendations}

It is expected that further research cover more complete variables, such as the rational use of antibiotics in the ICU, high infection in patients with ventilator uses, and so on. Future researchers could perform qualitative research design such as using in-depth interviews or FGD (focus group discussion) and using research methods in which objects can be monitored directly and continuously so that the results of the studies will be more comprehensive.

\section{Acknowledgment}

The authors thank to director of Pertamina Central Hospital, head of Intensicve Care Unit, head of Nursing Care Unit, head of Hospital Infection Control Unit, and all medical staffs (doctors and nurses) for supporting our research particularly during data collections and supporting materials.

\section{References}

[1] Ministry of Health, 2011. Guidelines of Infection Prevention in the Hospital and the Other Health Facilities; Preparedness of Emerging Infectious Disease. Jakarta.

[2] Department of Health, 2003. Guidelines on Infection Prevention and Control in the ICU, the Directorate General of Medical Services. Jakarta.

[3] Darmadi, 2008. Nosocomial Infections: Problematics and Control. Jakarta: Salemba Medika.

[4] Suwarni, A. 2001. Pattern descriptive study Environmental Health Efforts Mean length relationship with Genesis Day Care and Nosocomial Infection Case Study: Patients with Post-Surgical Inpatient Hospital Yogyakarta Provincial Government and Private Research Agency Year 1999 Department of Health and Social Welfare, Yogyakarta. Accessed December 25th, 2013. http://klikharry.wordpress.com/2006/12/21/infeksinosoco mial.

[5] Hurlock, E. B. 2001. Developmental Psychology. Tata: McGraw-Hill Education, 477.

[6] World Health Organization. 2009. Guidelines on Hand Hygiene in Health Care: First Global Patient Safety 

Indonesia Related to Healthcare Associated Infections

Challenge Clean Care is Safe Care.

[7] Czeresna, S. 2006. "Complete Assessment in Geriatric Patients." In Textbook of Medicine Volume III. New York: Publishing Center Department of Medicine Faculty of Medicine. 322: 1415-8.

[8] Richards, M. J., Edwards, J. R., Culver, D. H., and Gayness, R. P. 1999. Nosocomial Infection in Pediatric Intensive Care Units in United States. Accessed December 28 th,

2013. http://www.pediatrics.org/cgi/content/full/103/4/e39.

[9] Escallon J. 2003. Nutrition in Critical Care. In $A n$ Integrated Approach to Patient Care Total Nutritional
Therapy, edited by McCarnish, M. Pennsylvania: Elsevier, 117-28.

[10] Malangoni, M. A. 1997. Critical Issuess in Operating Room Management. Philadelpia: Lippincott-Raven, 133-49.

[11] Santoso. 2009. Wound Healing. Accessed October 30th, 2013.

http://www.Dr.Budhi.Santoso@ho.otsuka.co.id/2009/10/ 28/penyembuhan-luka.html/.

[12] Yelda, F. 2003. "Risk Factors that Influence against Nosocomial Infection in Some Hospitals in Jakarta.” M.S. thesis, Faculty of Public Health, Universitas Indonesia. 